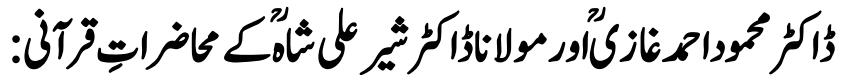

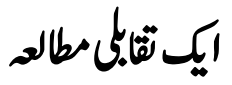

\section{A Comparative Study of Quranic Lectures of Dr.Mahmood Ahmad Ghazi and Maulana Dr. Sher Ali Shah}

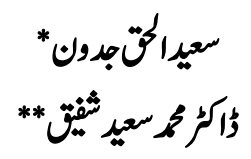

\begin{abstract}
The teaching and learning of Quran is a great blessing that is why the Islamic scholar have played a pivotal role in this regard. They also intensified their efforts immensely in publishing of Quranic knowledge. Allah took great services of Quranic words and meanings fromUlama and Islamic Researchers. The modern age due to specialization which were introduced in the Holy Quran, among these one is Quranic lectures. The monumental scholars, Researchers and the experts of Quranic Knowledge deliver lectures on different subjects from which general and specific people take advantage equallly. This kind of teaching adopted the shape of permanent Art in the modern era.
\end{abstract}

Dr. Mahmood Ahmad Ghazi and maulana Dr. Sher Ali Shah were also international level scholars and researchers, who were called upon by the people for Quranic lectures in country and foreign.

The Quranic lectures delivered by Dr Mahmood Ahmad Ghazi and Dr.Sher Ali Shah were very beneficial for Quranic students and scholars. In this Article we discuss Comparative Study of Quranic lectures of Dr. Mahmood Ahmad Ghazi and Molana Dr. Sher Ali Shah.

Key Words: Comparative Study, Mehmood Ahmed Ghazi, Maulana Dr. Sher Ali Shah, Quranic Lectures, Beneficial

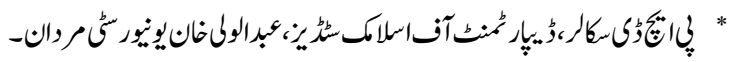

$$
\begin{aligned}
& \text { | }
\end{aligned}
$$




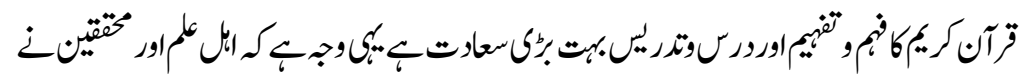

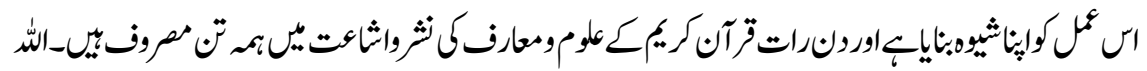

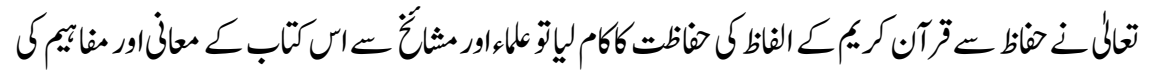

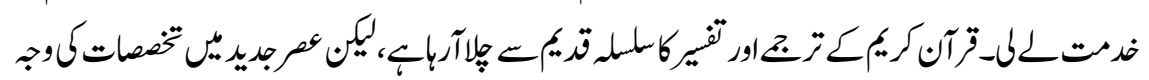

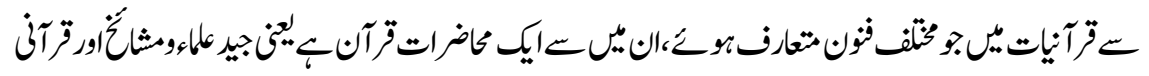

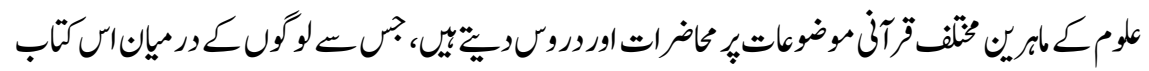

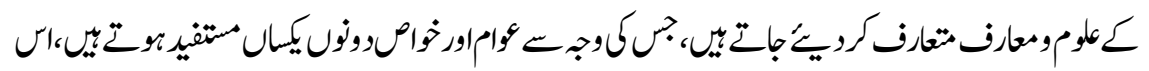

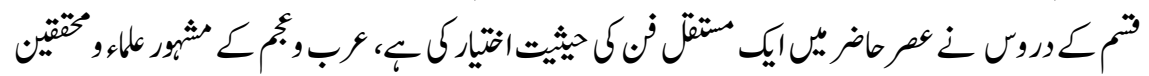

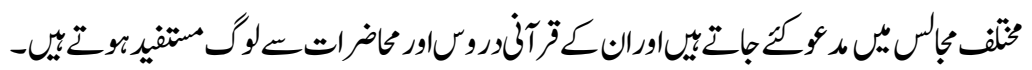

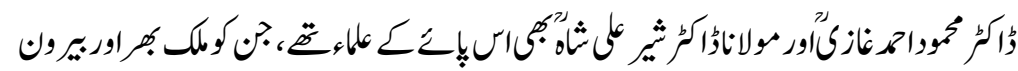

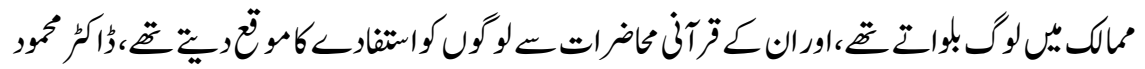

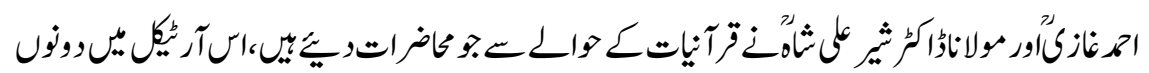

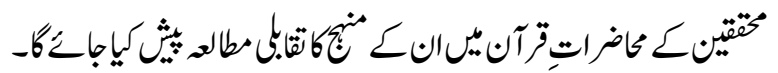

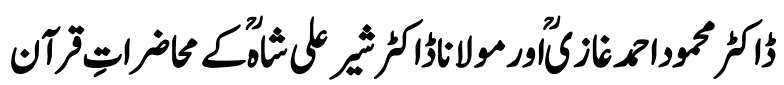

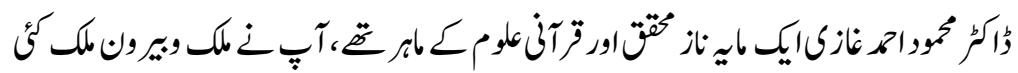

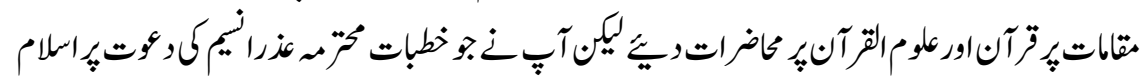

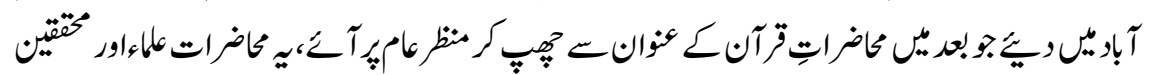

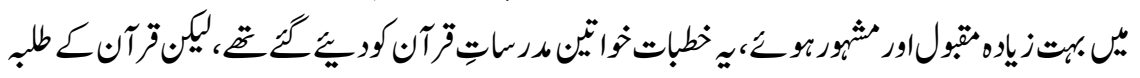

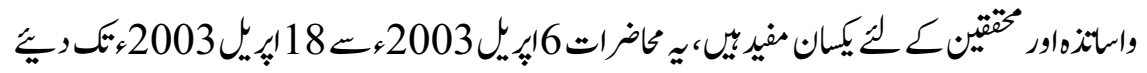

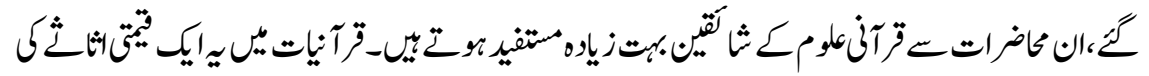

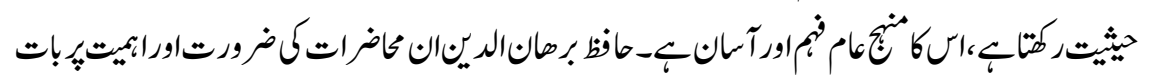

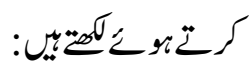

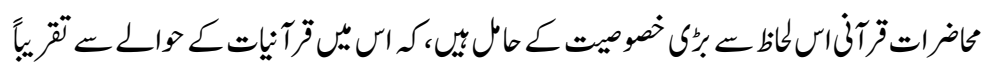

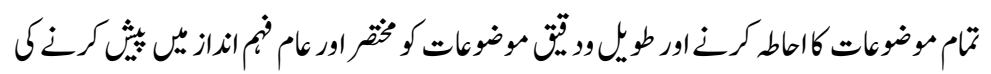




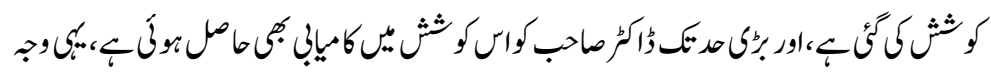

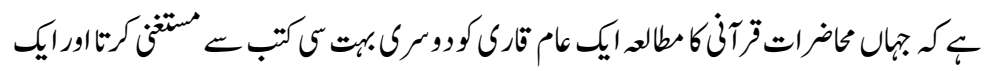

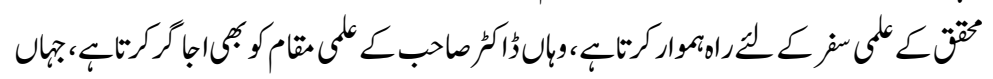

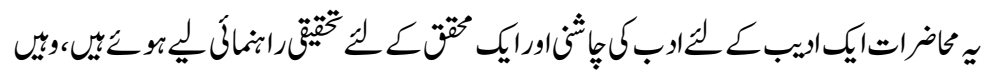

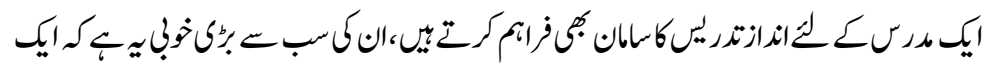

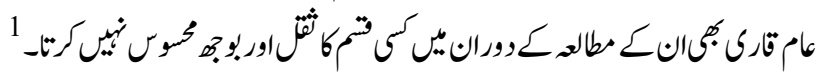

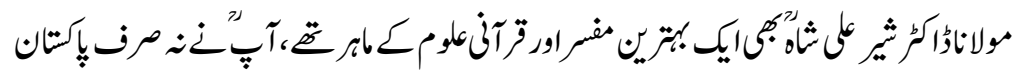

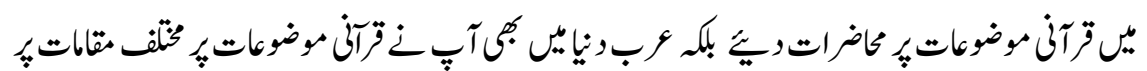

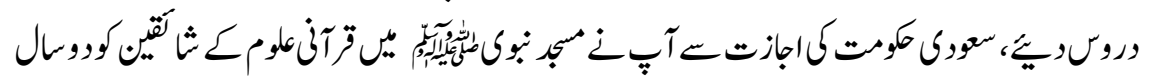

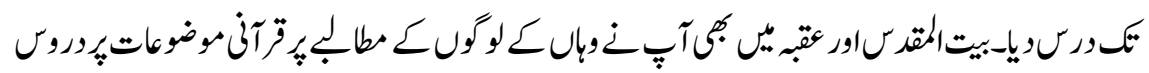

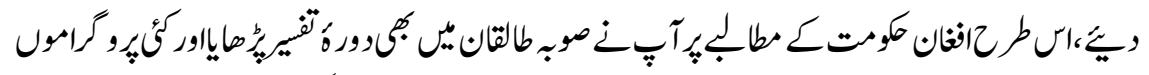

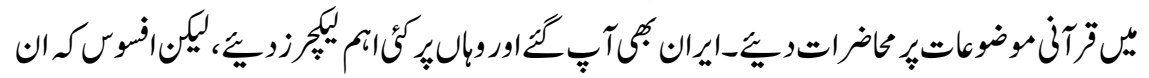

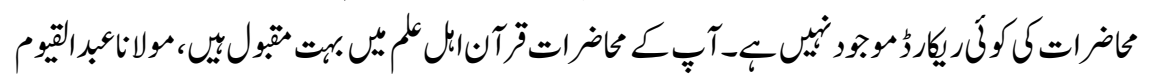

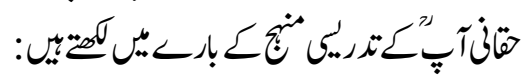

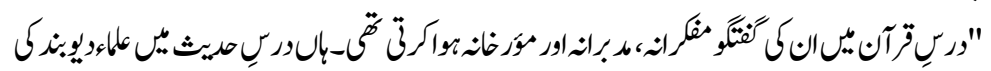

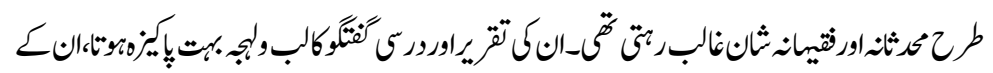

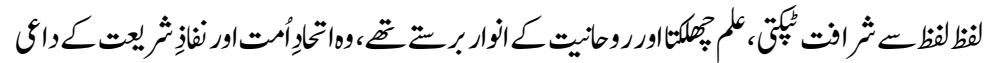

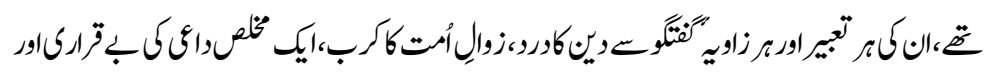

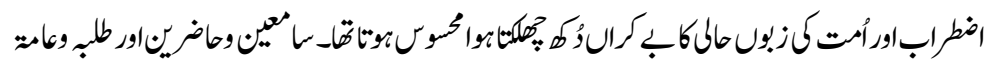

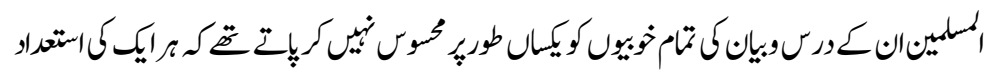

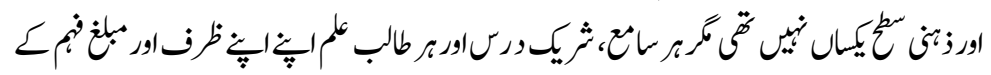

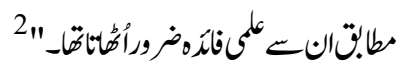

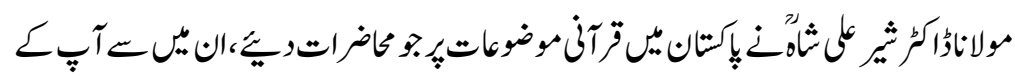

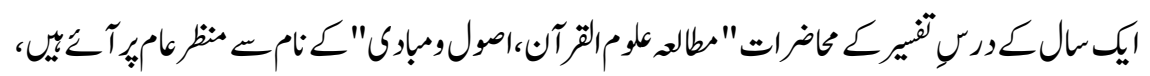

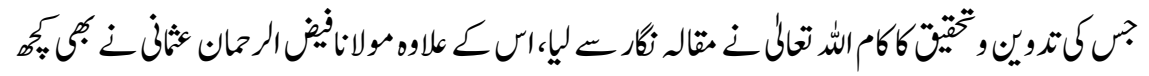




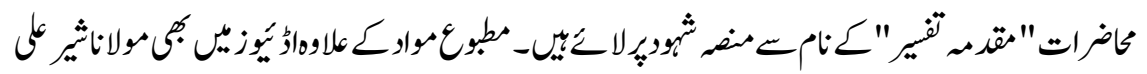

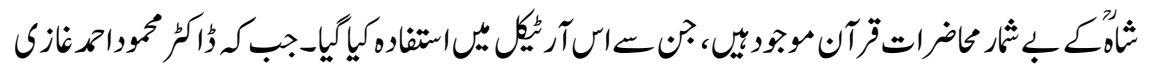

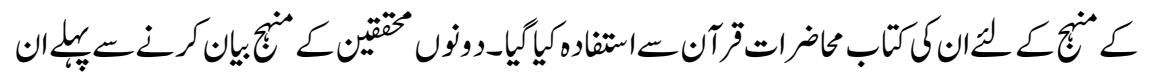

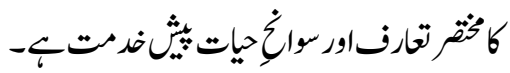

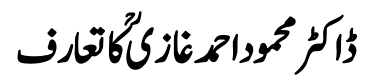

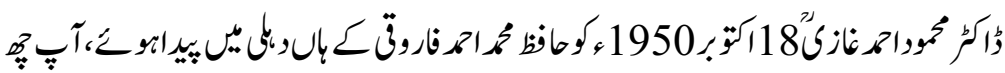

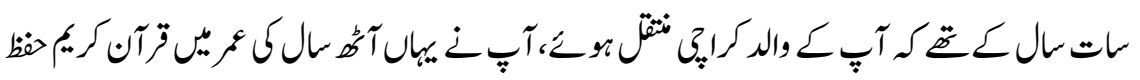

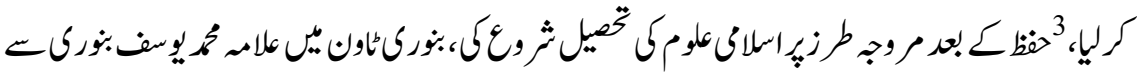

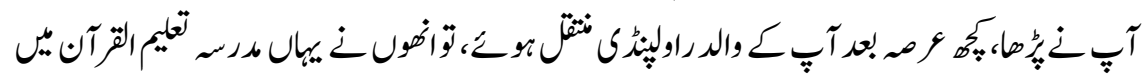

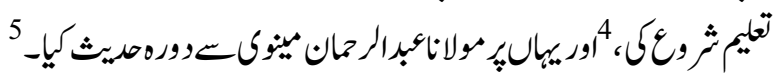

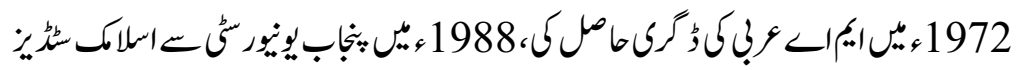

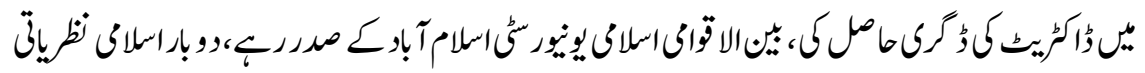

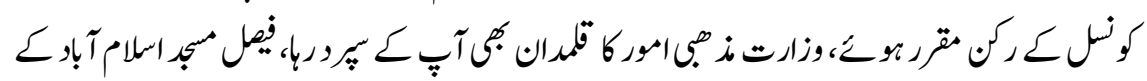

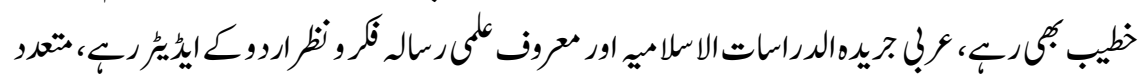

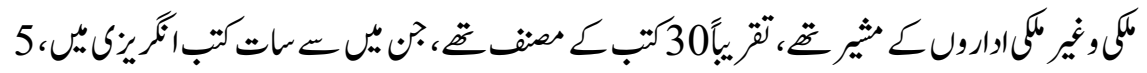

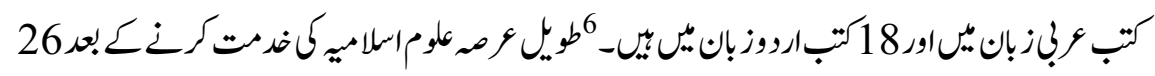

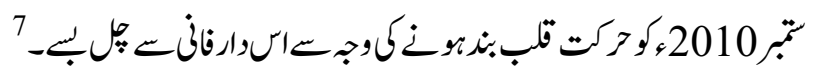

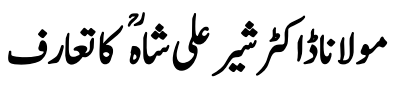

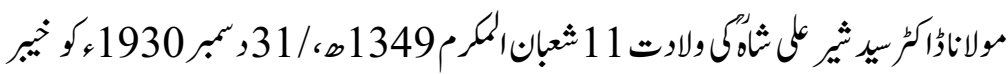

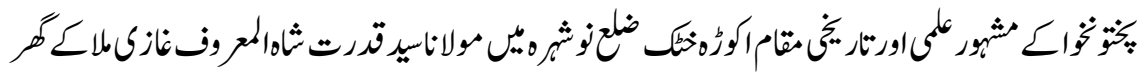

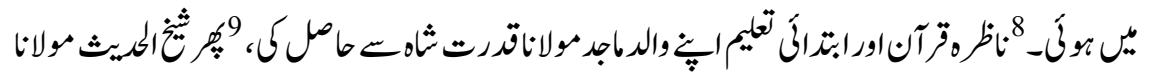

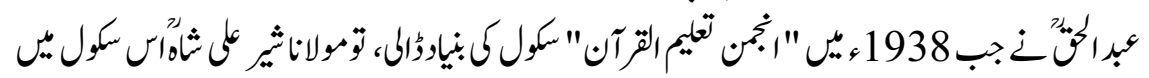

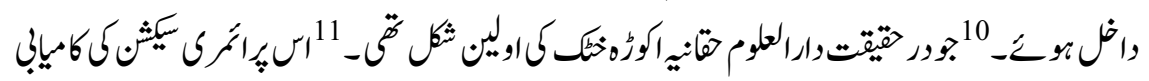




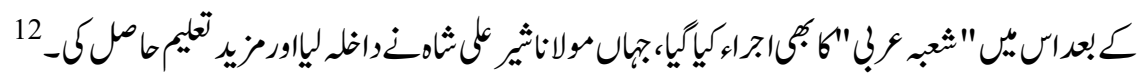

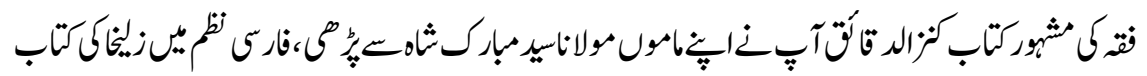

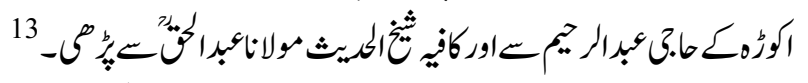

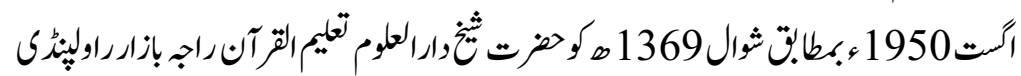

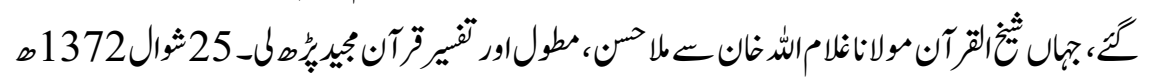

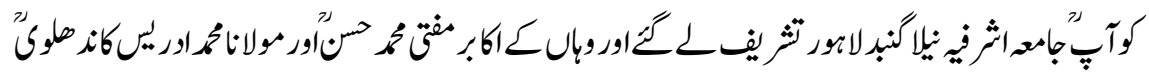

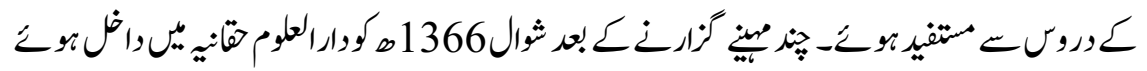

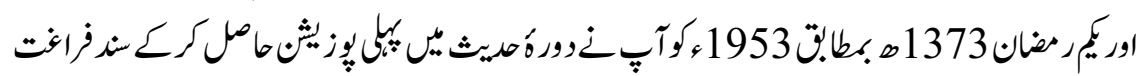

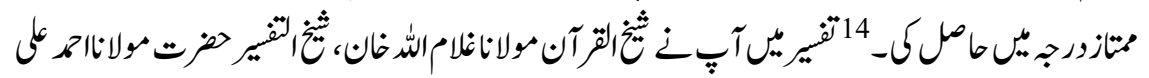

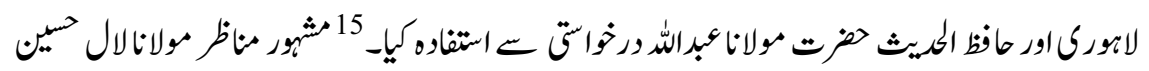

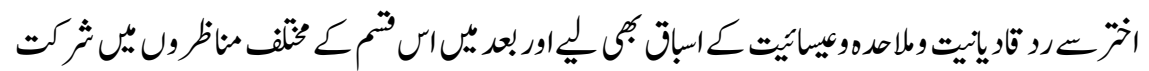

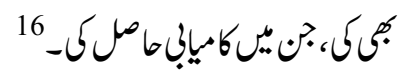

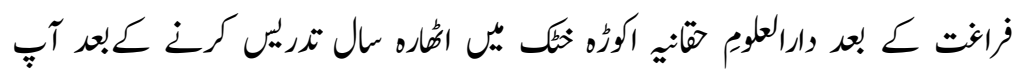

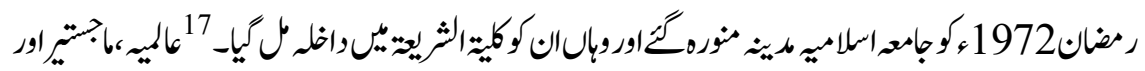

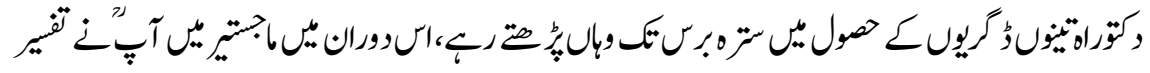

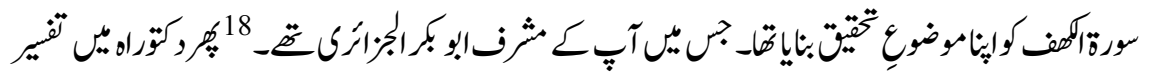

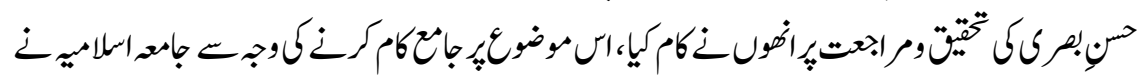

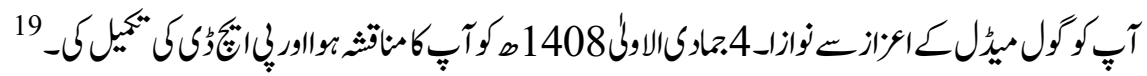

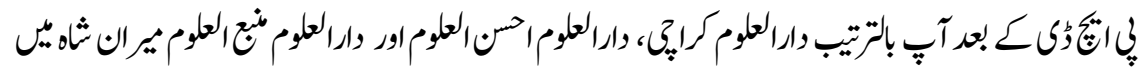

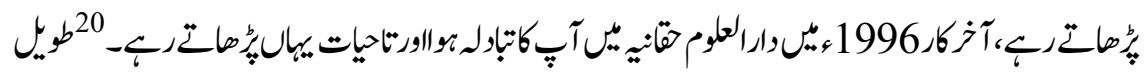

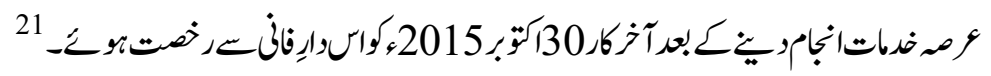

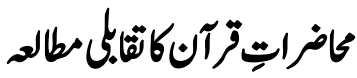

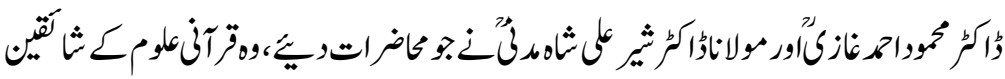

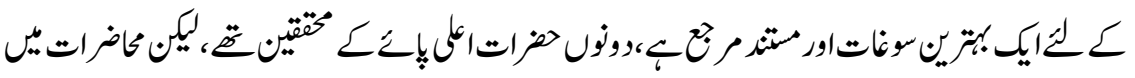




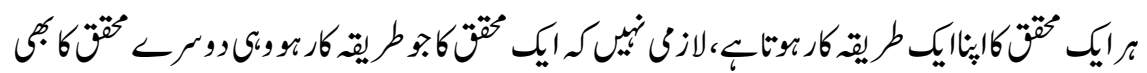

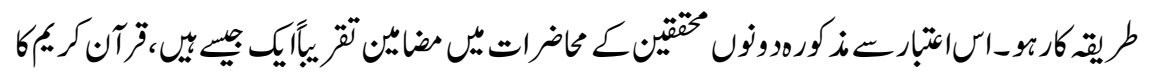

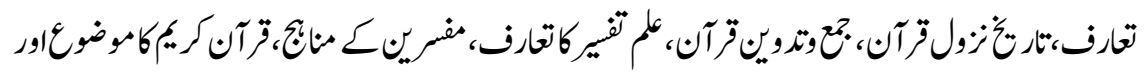

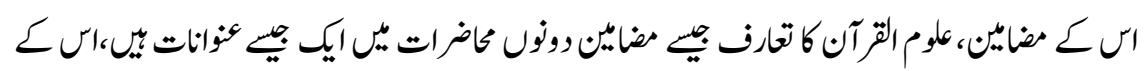

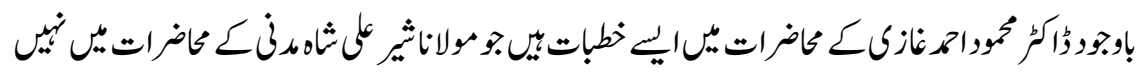

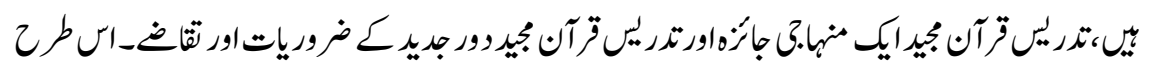

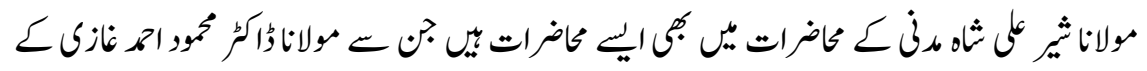

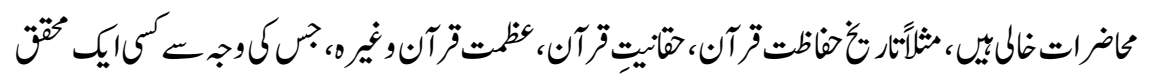

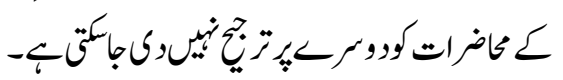

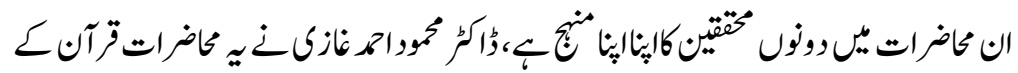

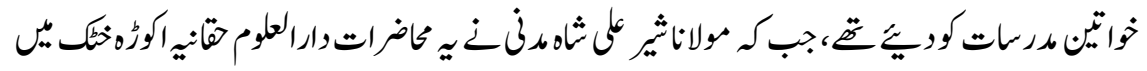

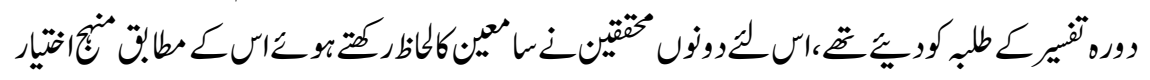

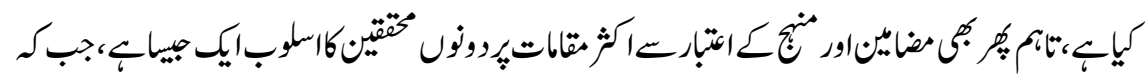

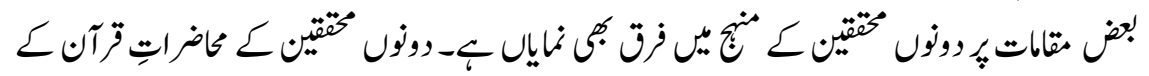

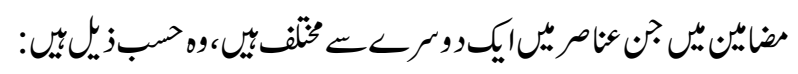

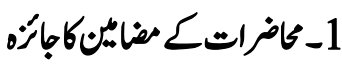

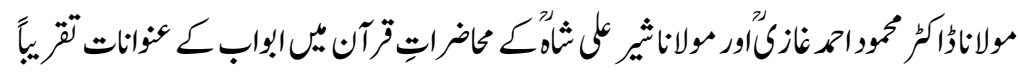

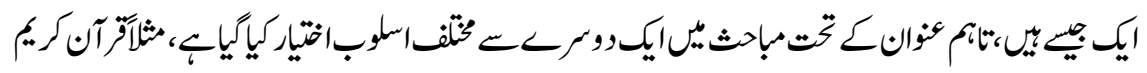

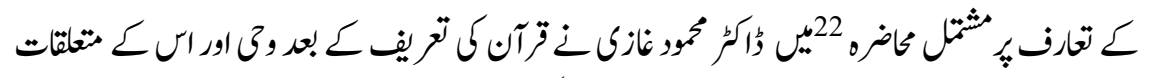

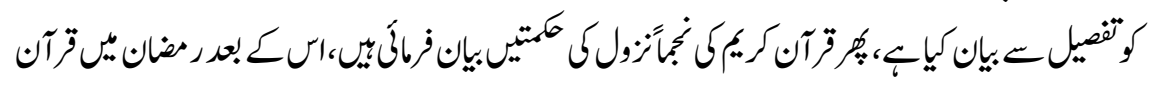

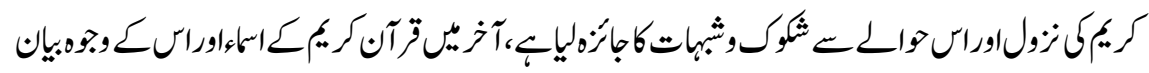

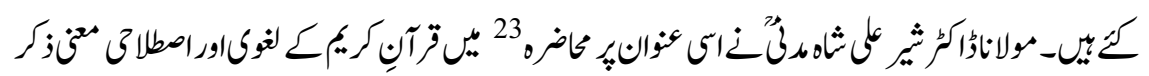

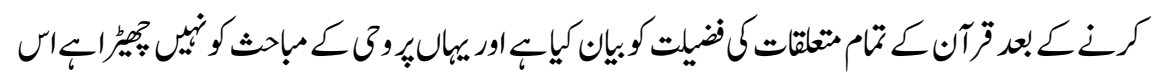

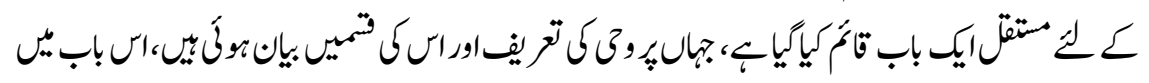




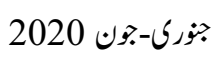

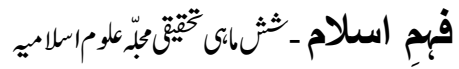

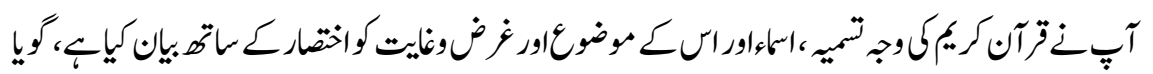

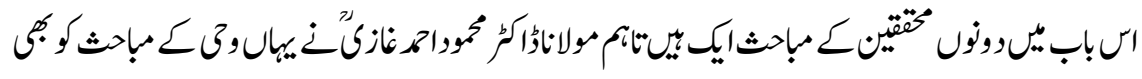

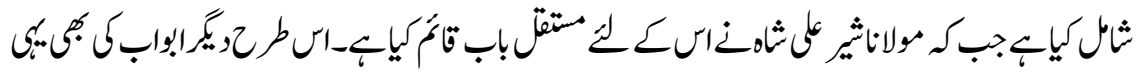

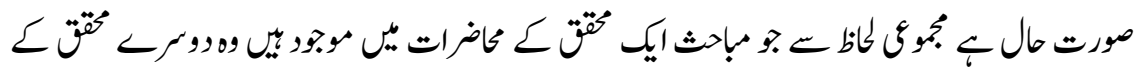

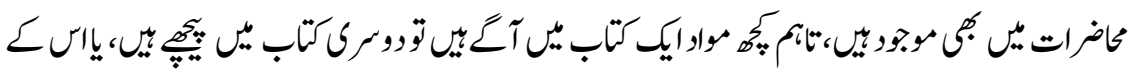

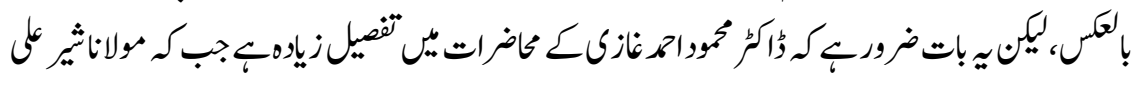

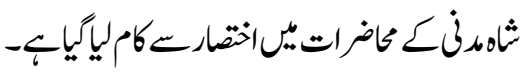

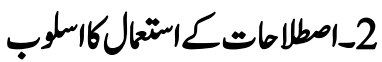

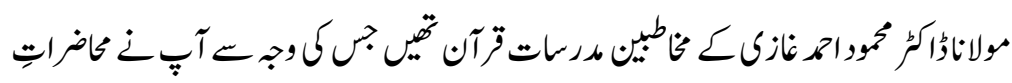

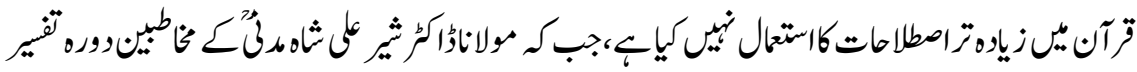

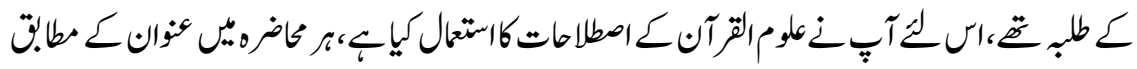

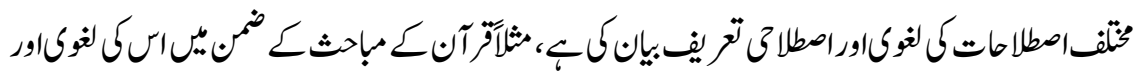

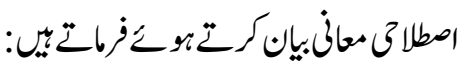

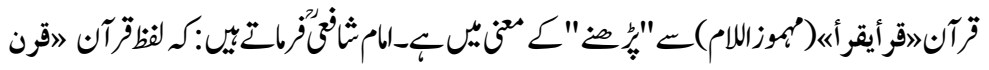

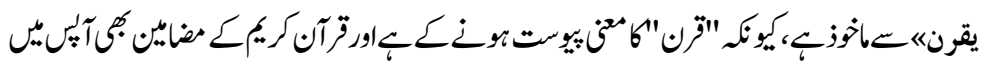

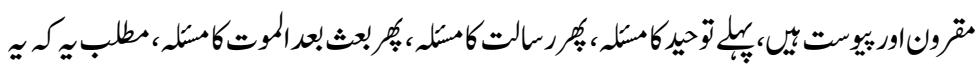

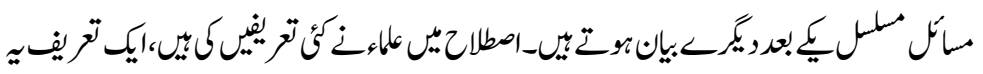
ب: "هو الكتاب المنزل على رسوله المكتوب في المصاحف المنقول عنه نقلاًمتواتر آبلاشبهة)

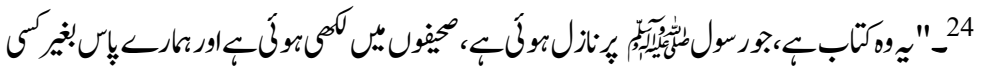

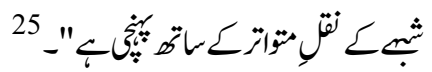

3_عام فمثالوس

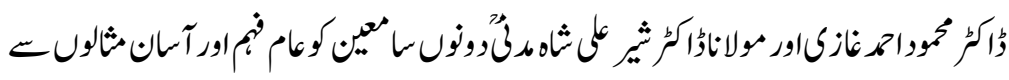

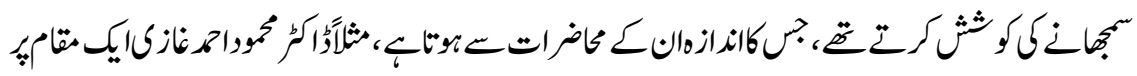

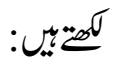

109 


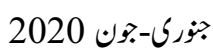

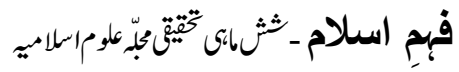

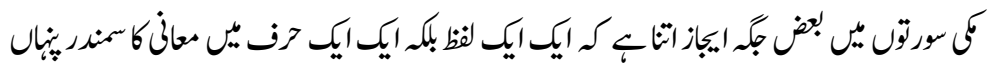

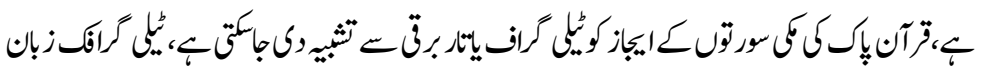

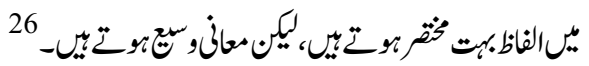

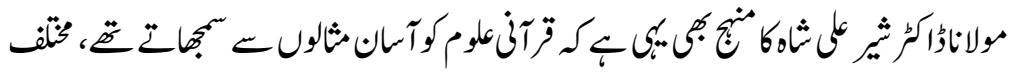

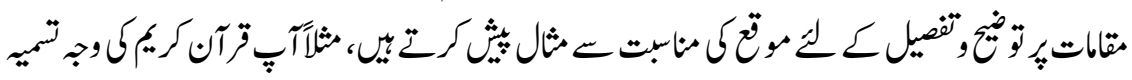

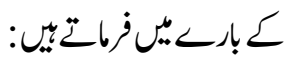

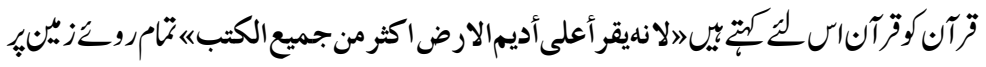

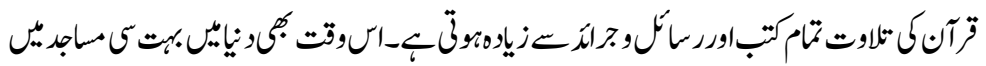

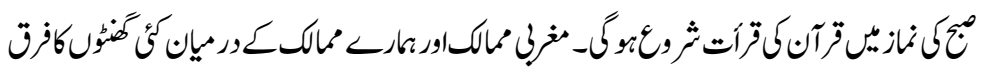

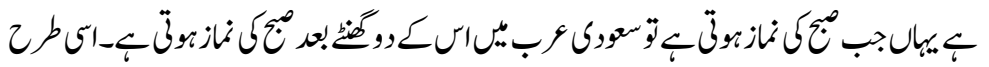

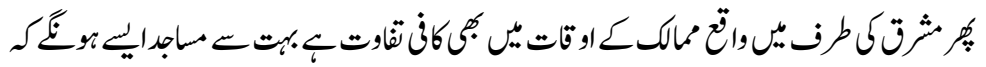

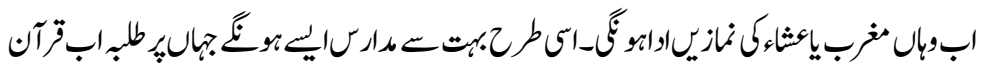

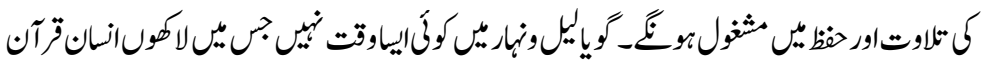

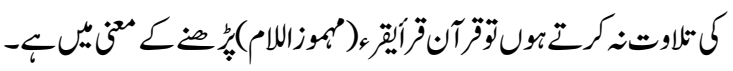

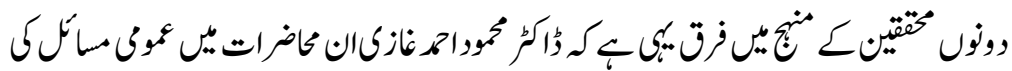

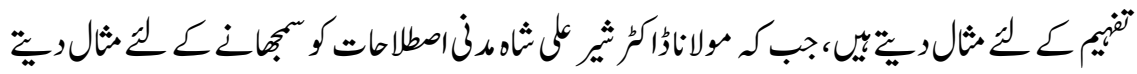

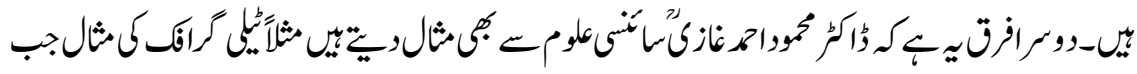

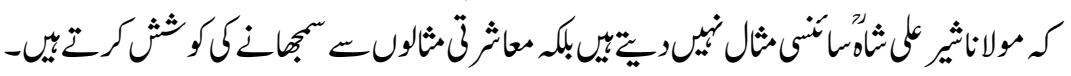

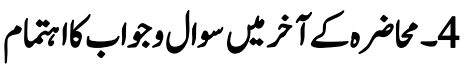

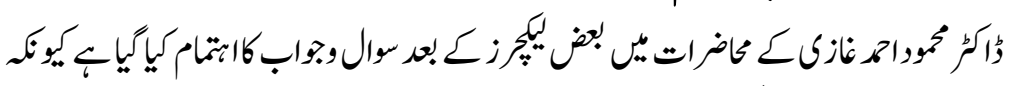

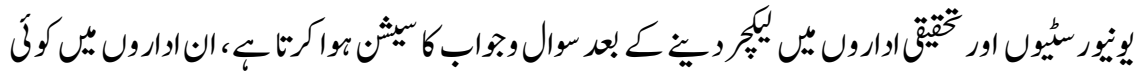

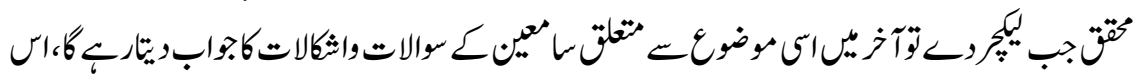

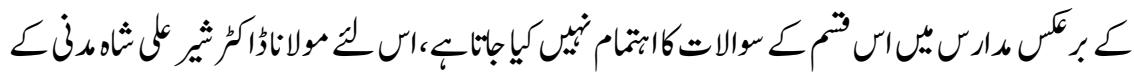

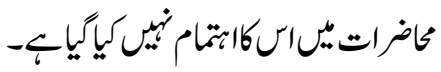

110 


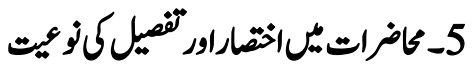

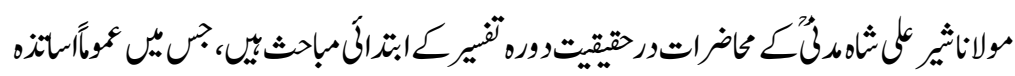

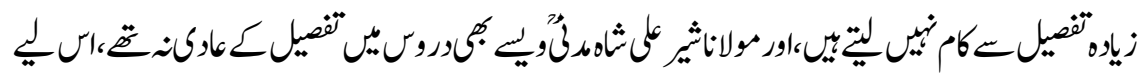

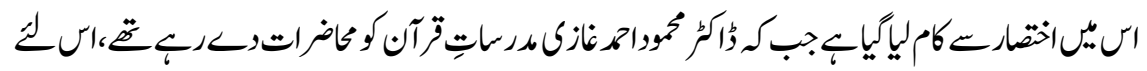

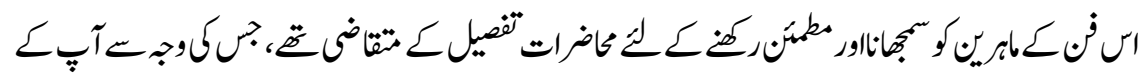

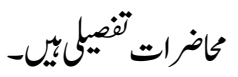

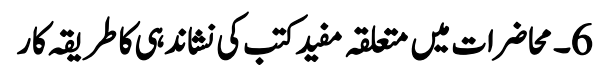

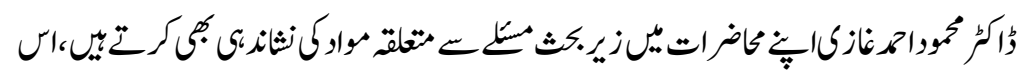

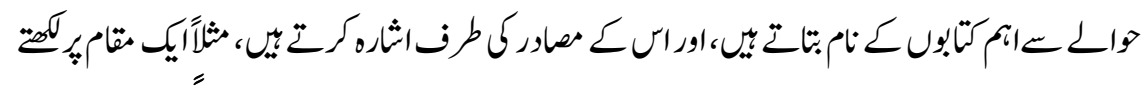
ب.

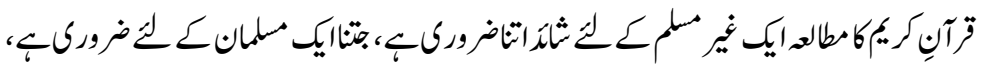

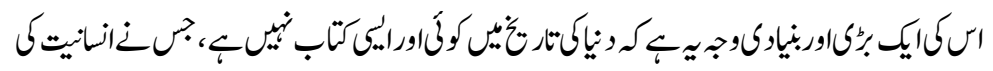

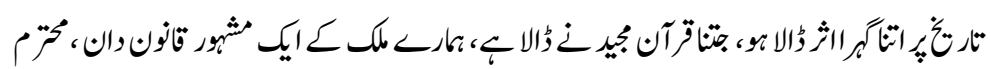

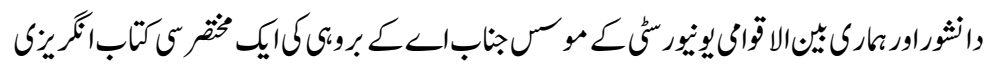

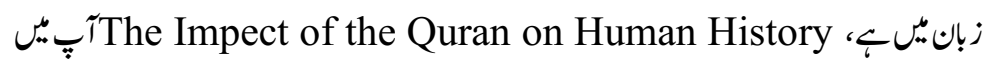

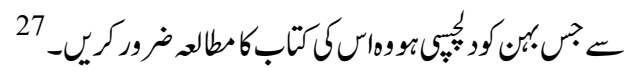

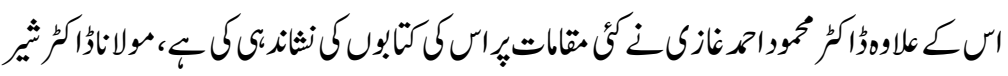

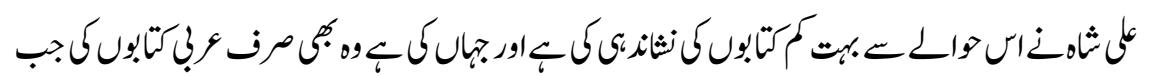

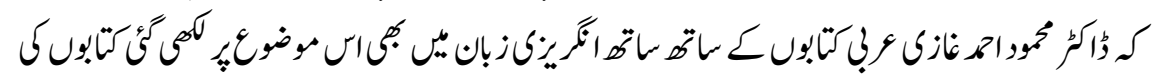

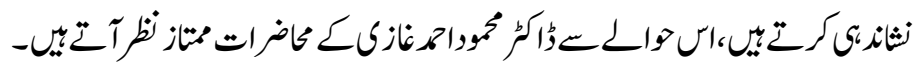

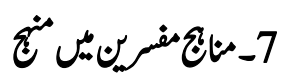

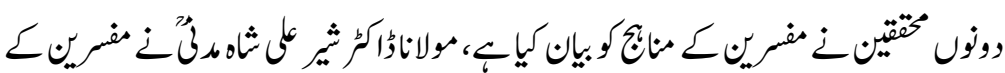

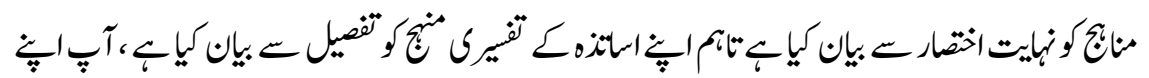

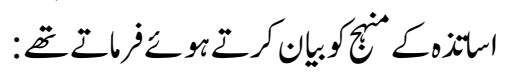




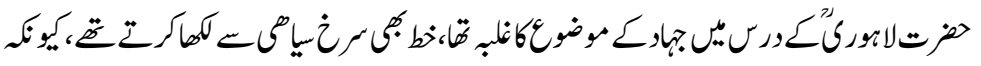

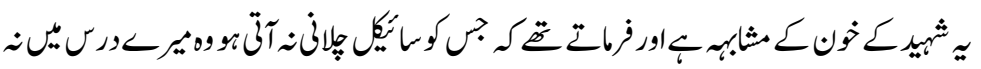

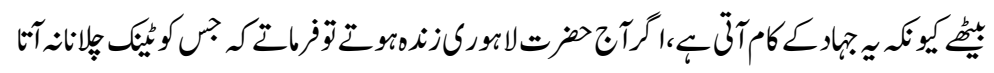

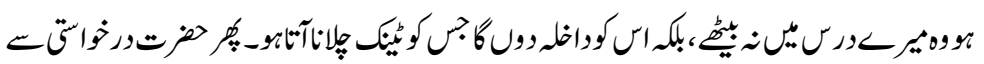

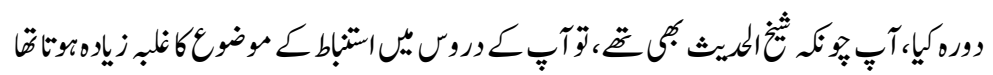
28 ?

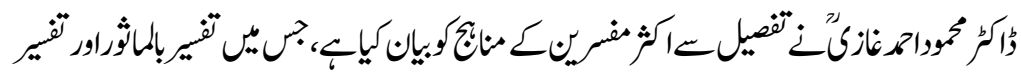

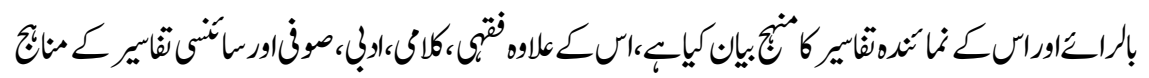

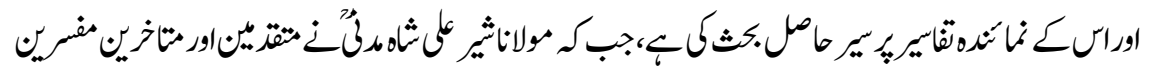

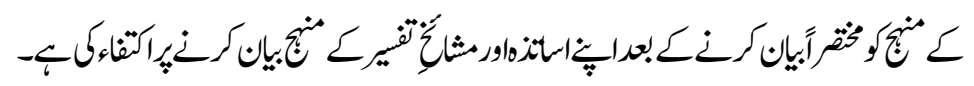
8_ارواشعارس اتترلالكارسلوب

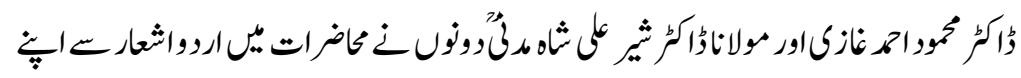

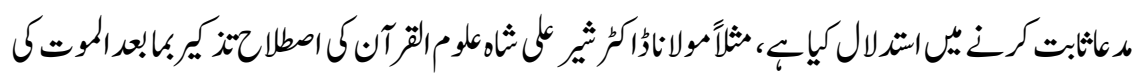

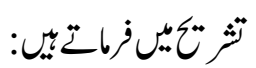

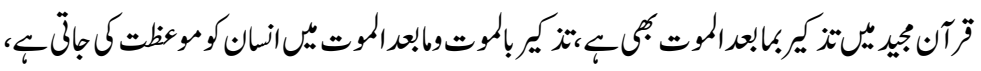

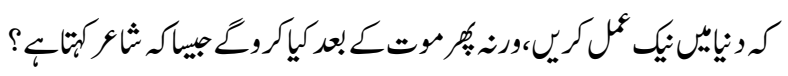

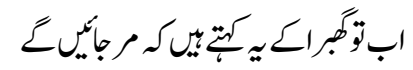
29

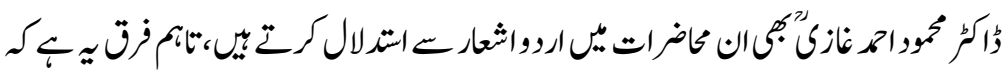

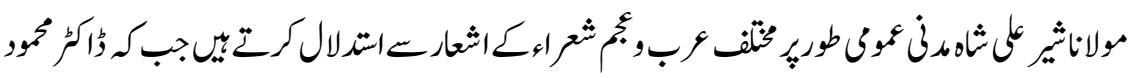

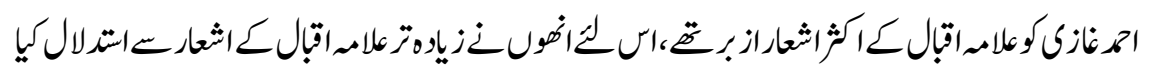

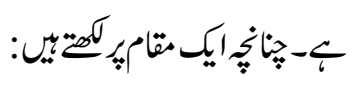

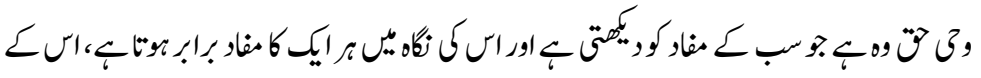

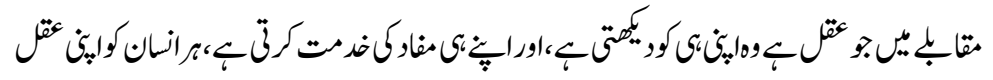




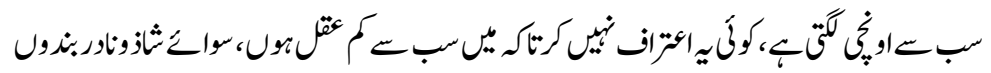

$$
\begin{aligned}
& \text { ك، علامزواتيك: }
\end{aligned}
$$

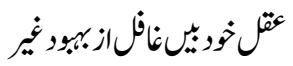

$$
\begin{aligned}
& 30 \text { بورغوبينين }
\end{aligned}
$$

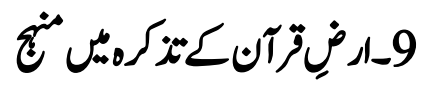

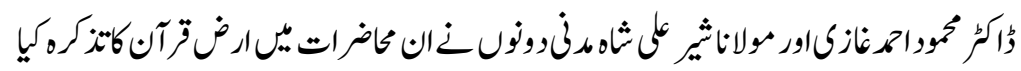

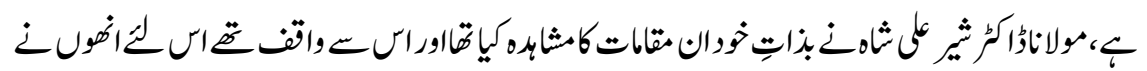

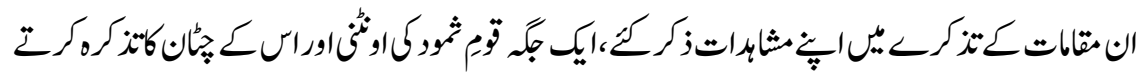
:

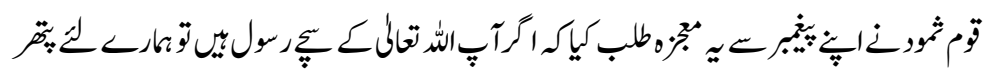

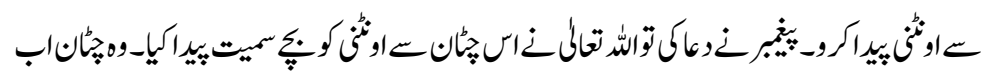

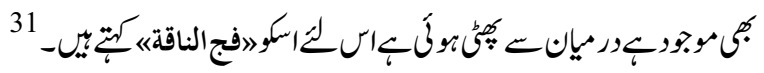

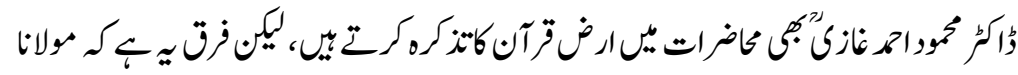

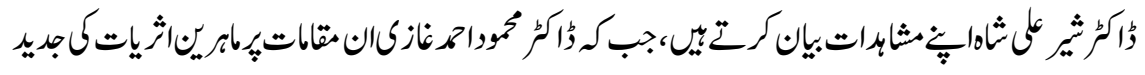

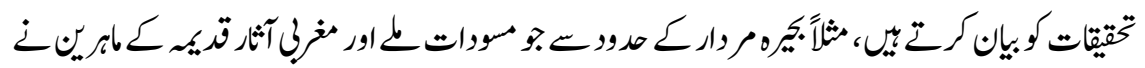

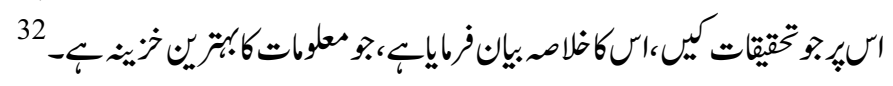

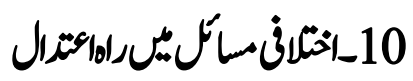

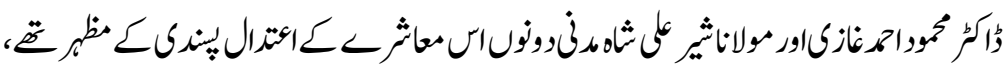

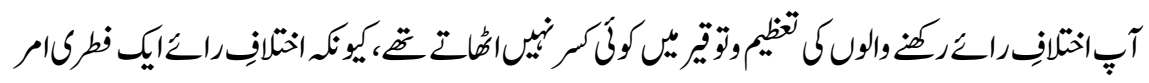

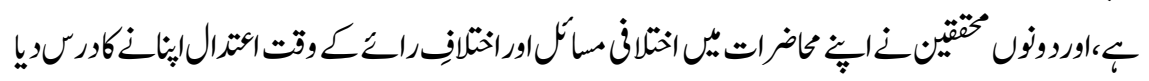

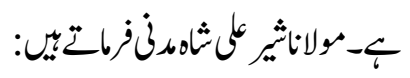




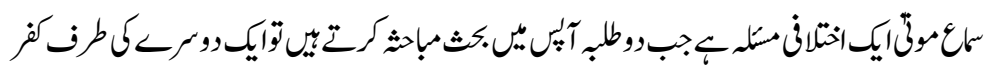

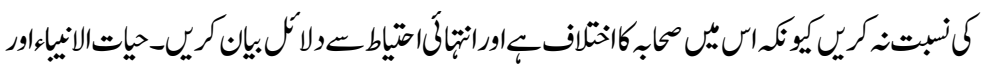

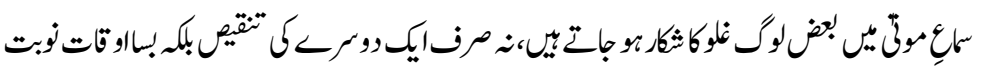

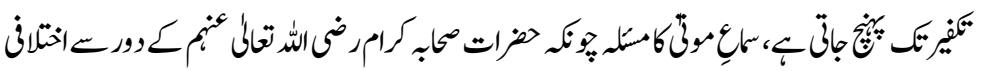

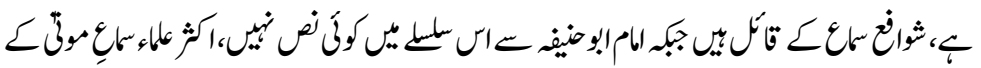

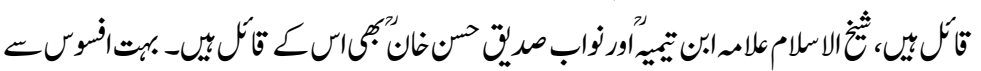

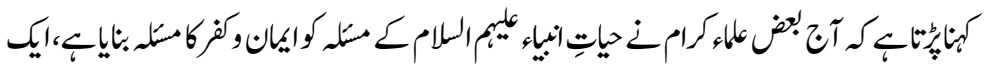

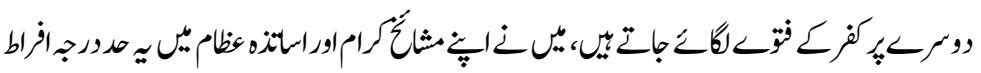

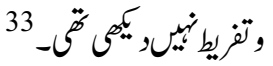

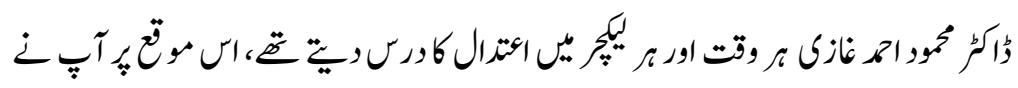

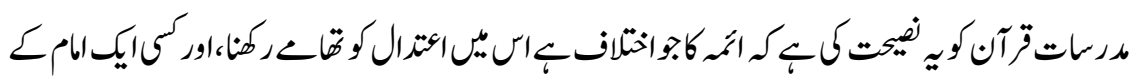

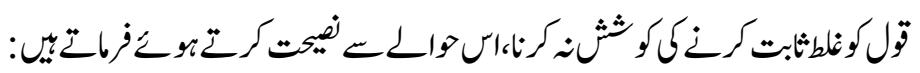

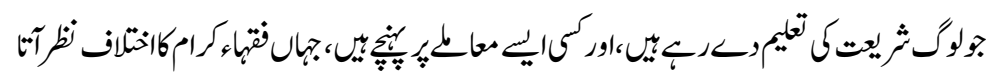

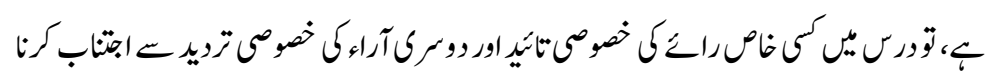

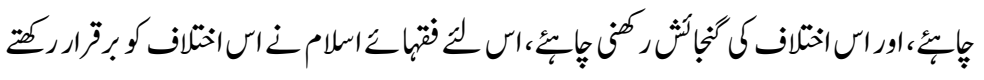

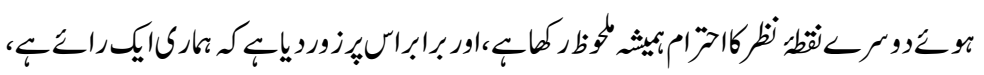

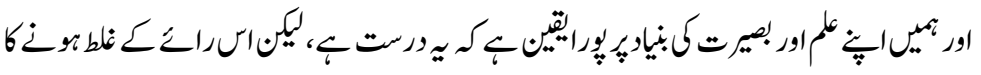

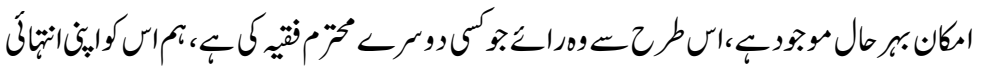

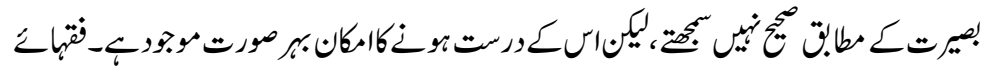

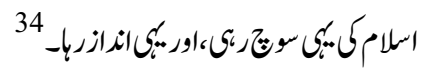

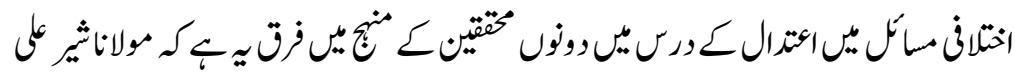

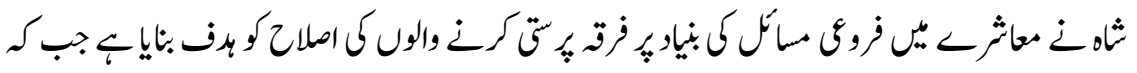

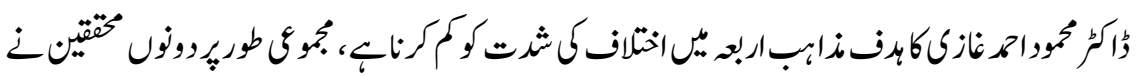

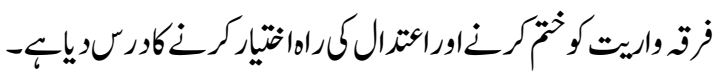




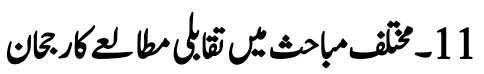

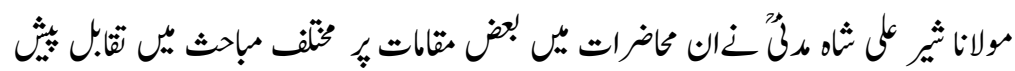

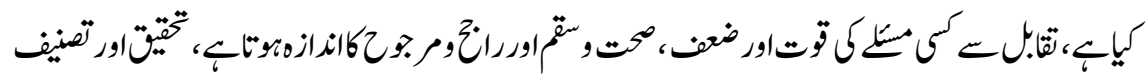

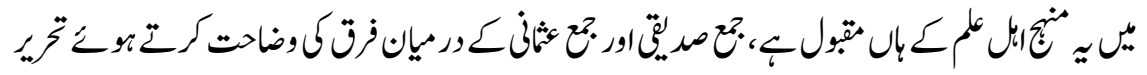
ز

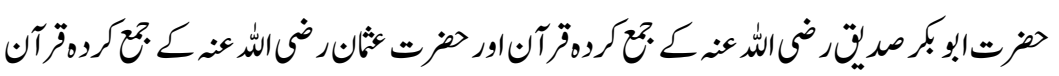

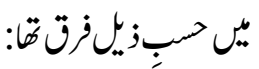

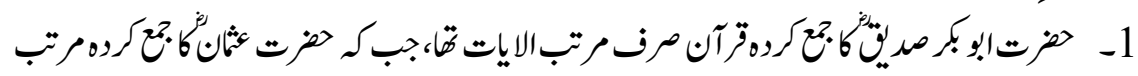

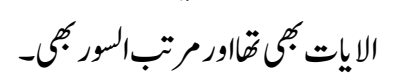

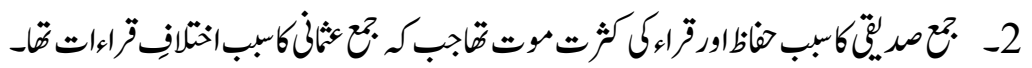

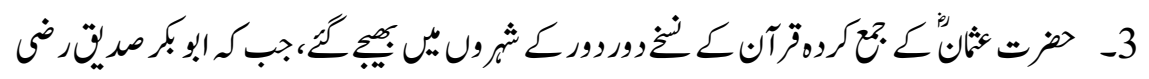

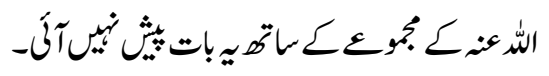

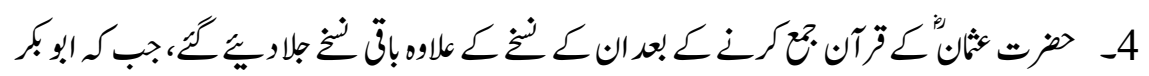

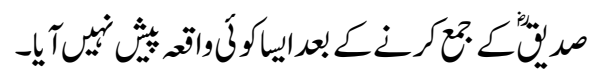

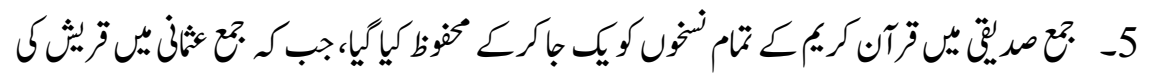

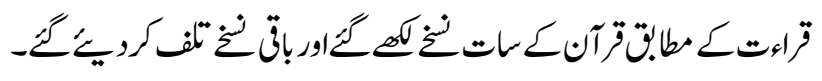

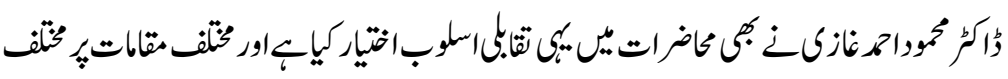

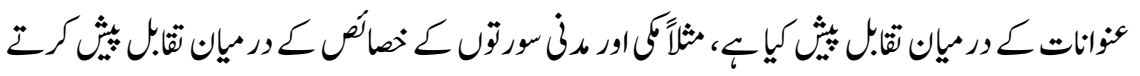

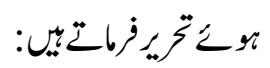

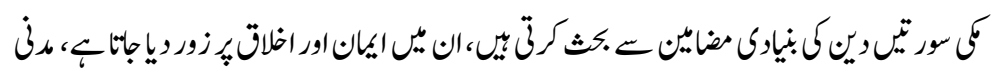

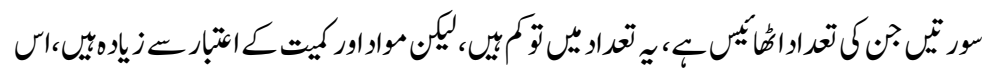

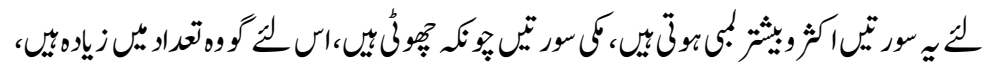

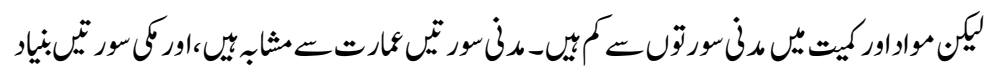

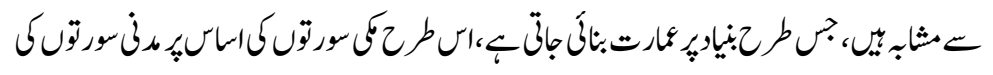




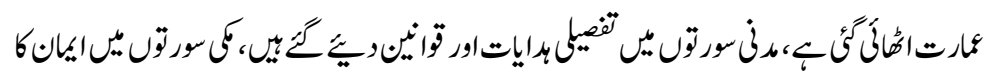

$$
35-60
$$

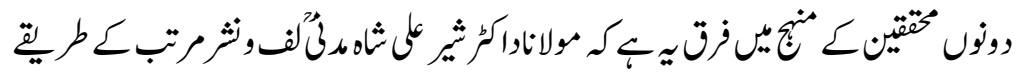

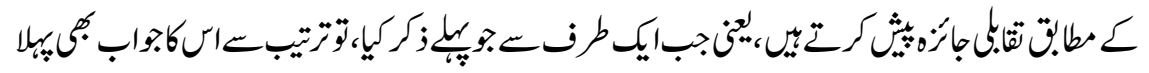

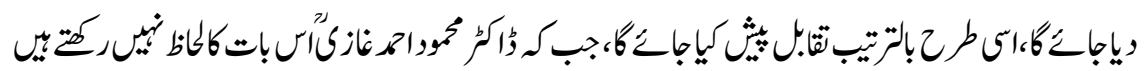

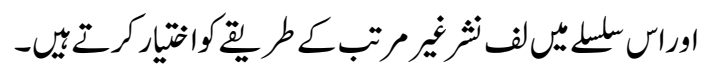

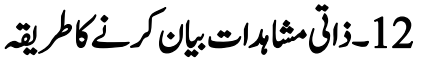

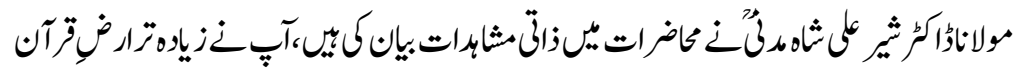

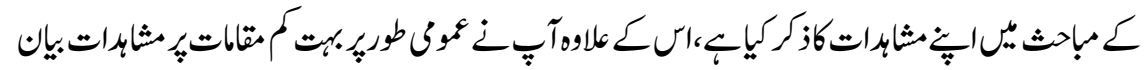

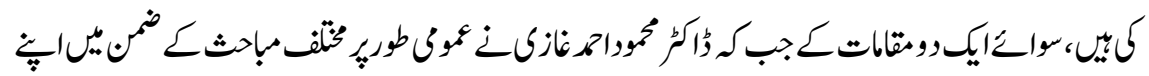

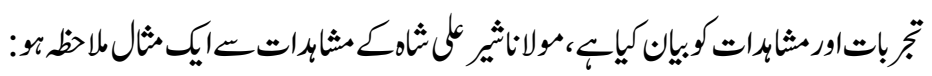

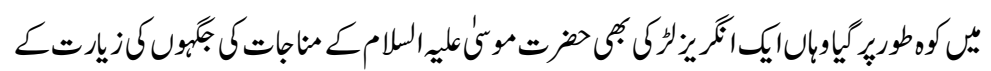

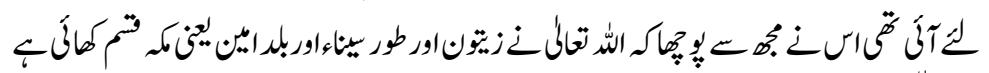

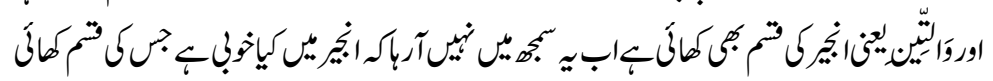

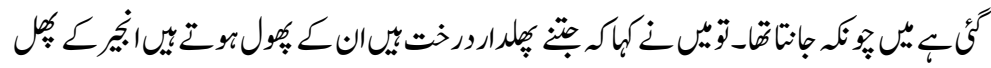

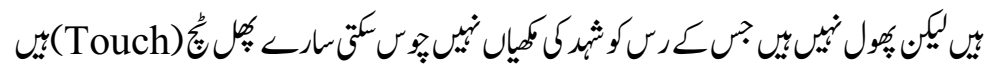

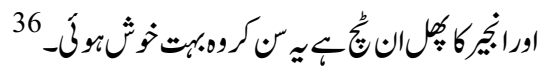

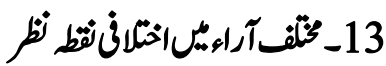

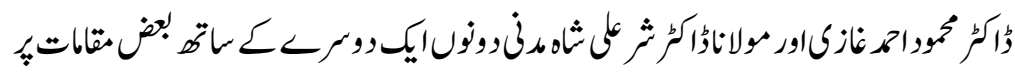

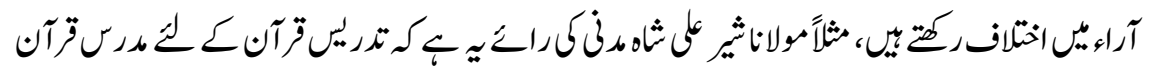

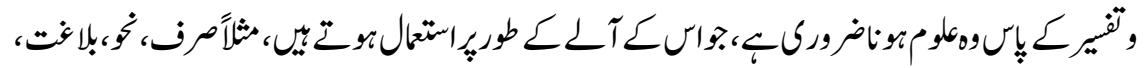

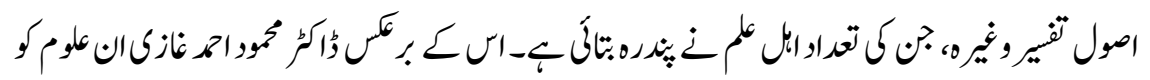

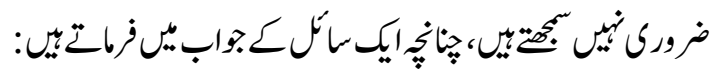




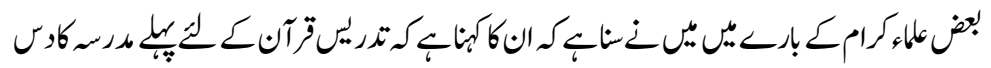

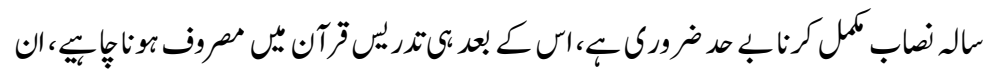

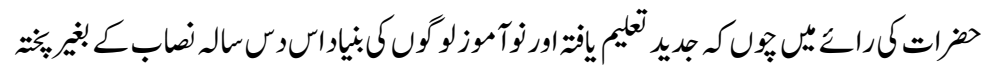

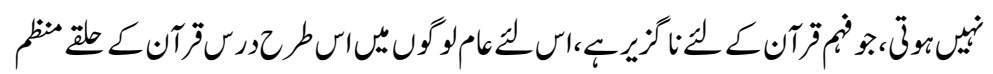

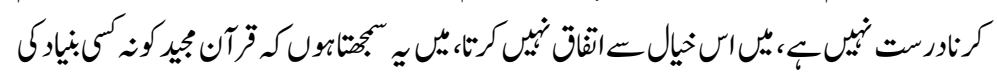

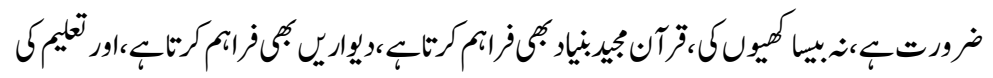
تئيل بكاكرثاب

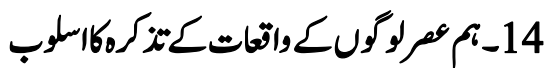

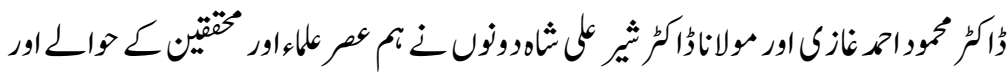

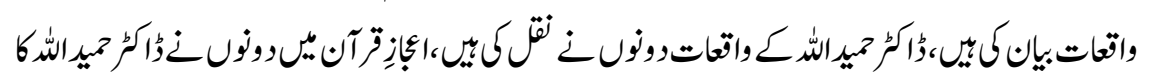

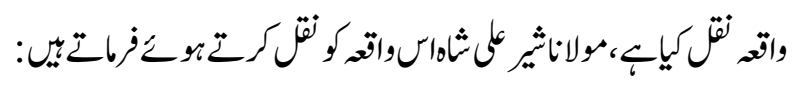

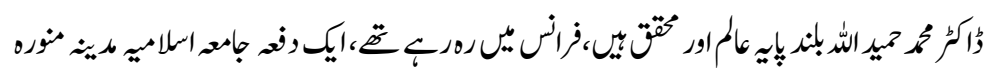

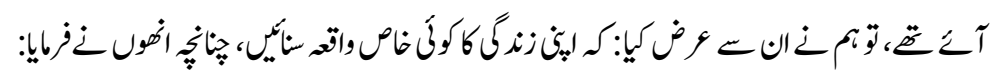

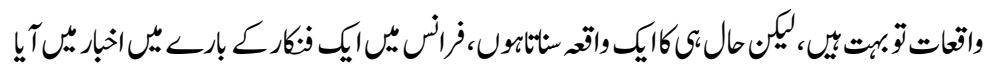

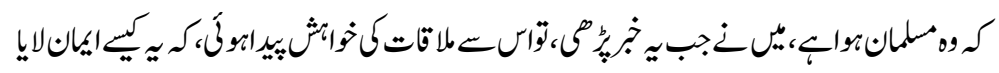

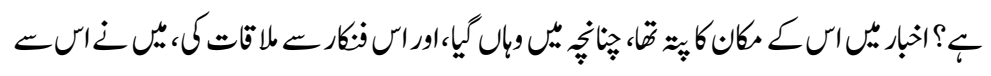

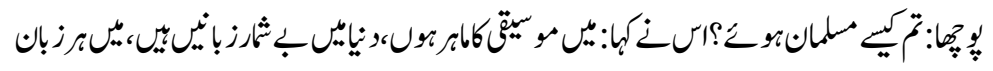

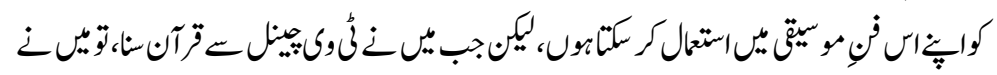

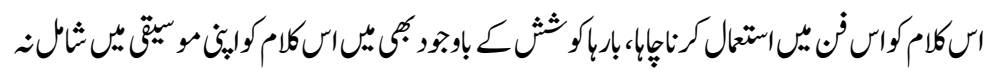

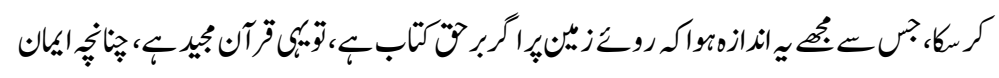

$$
\text { لايا،اور مسلمان بوا- } 38
$$

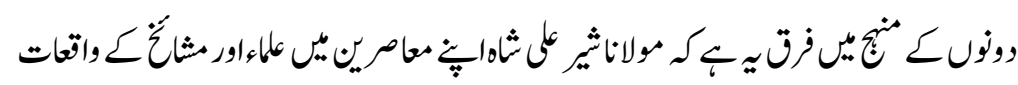

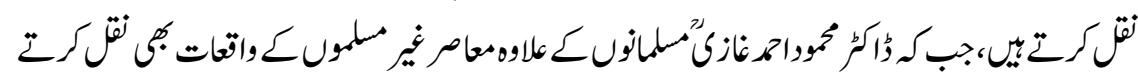

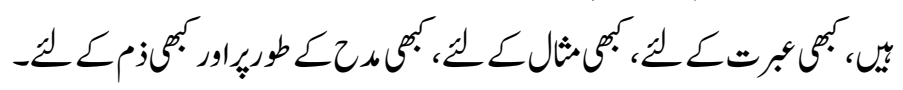




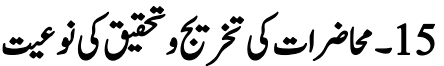

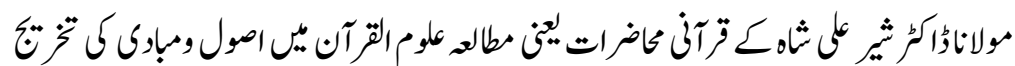

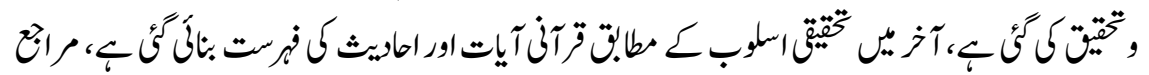

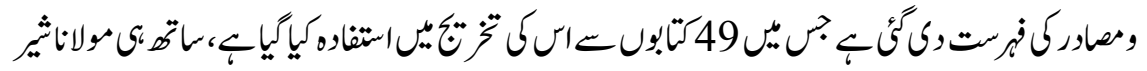

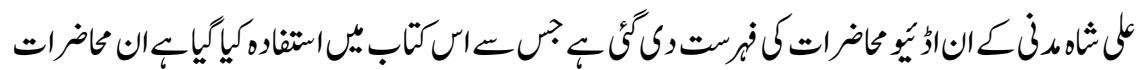

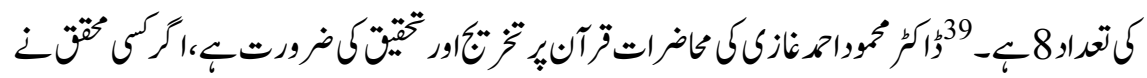

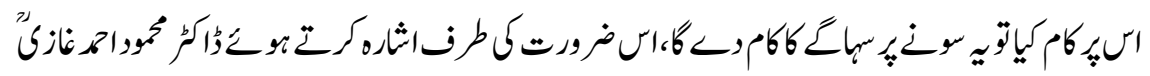
زماتئ:

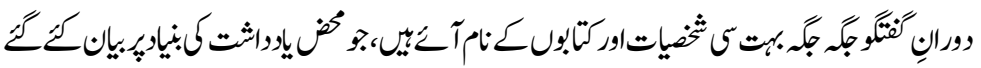

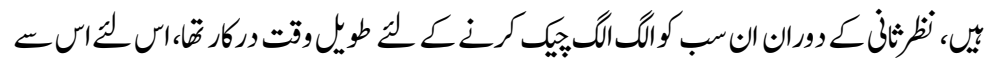

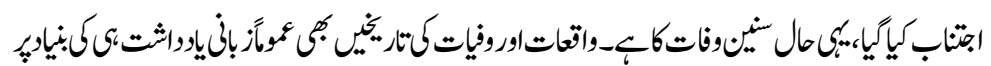

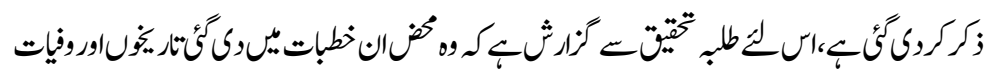

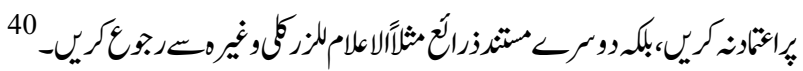

\section{ملاصم كلام}

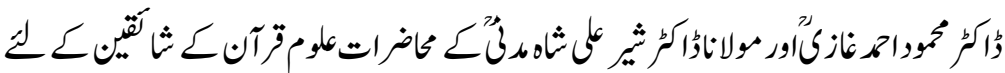

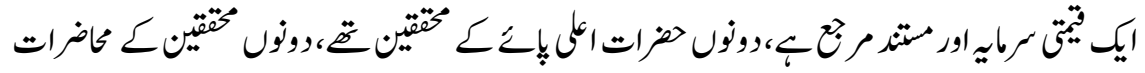

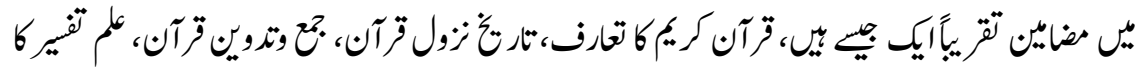

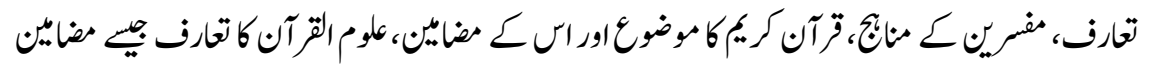

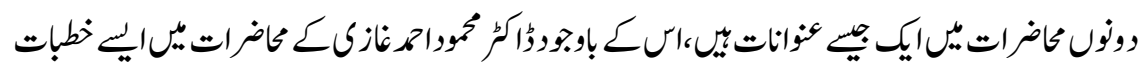

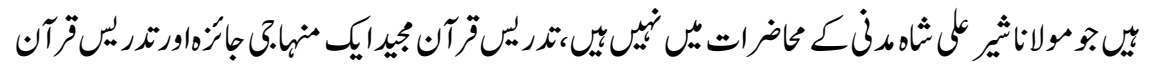

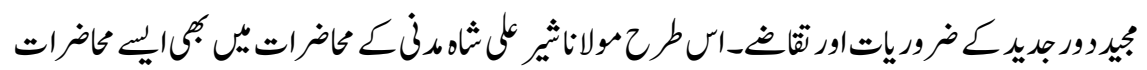

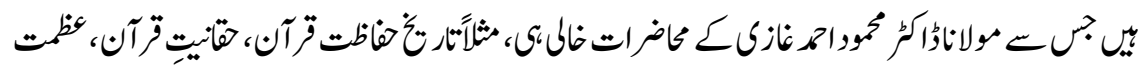

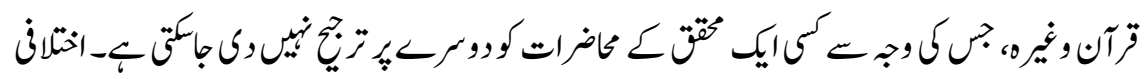




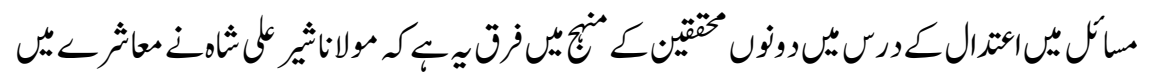

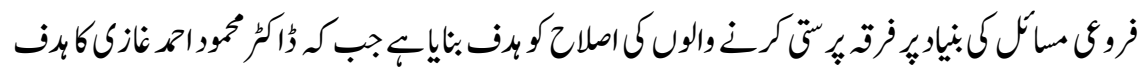

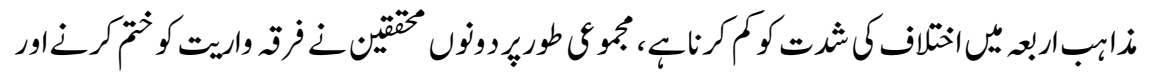

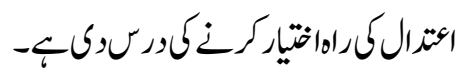

\section{واثَّوحالمجات}

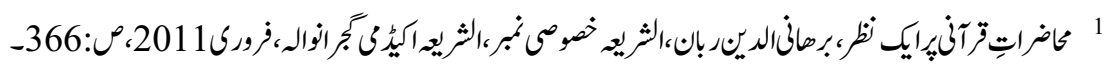

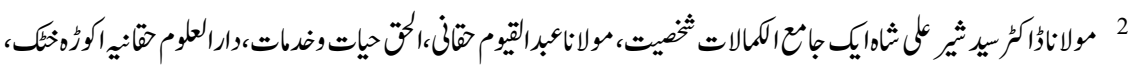
ص:-47

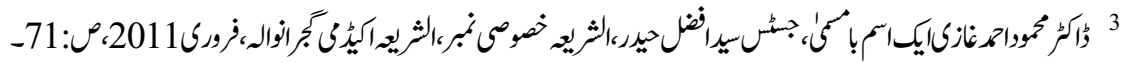

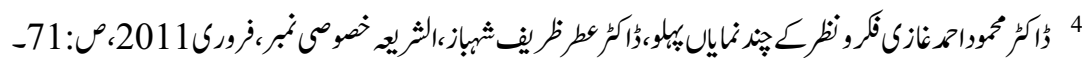

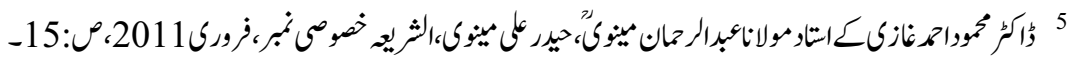

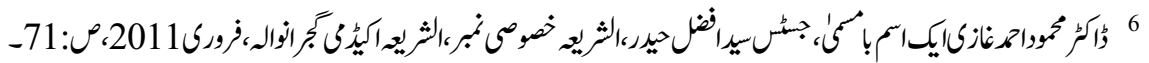

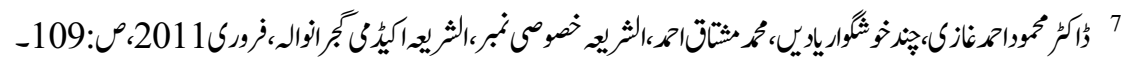

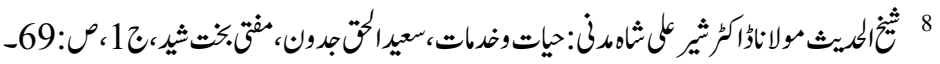

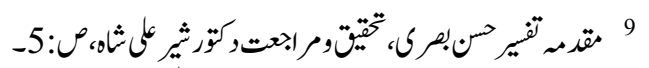

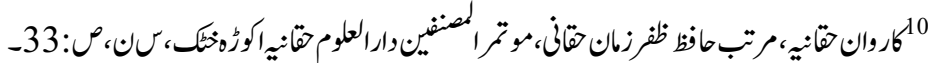

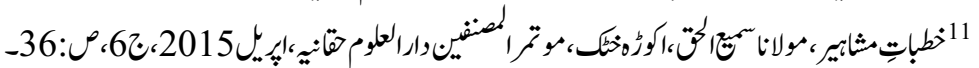

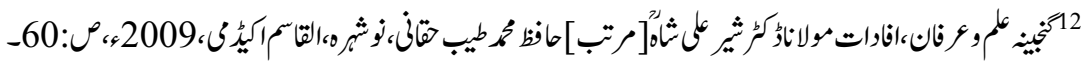

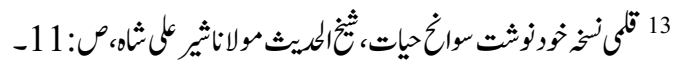

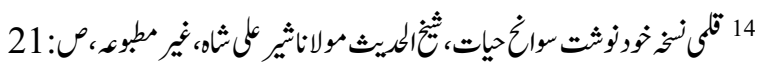

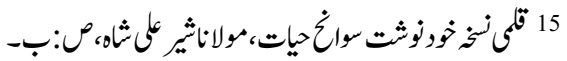

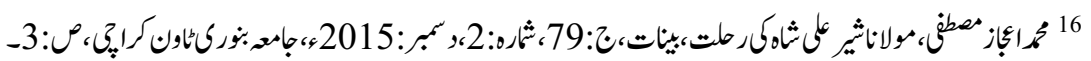

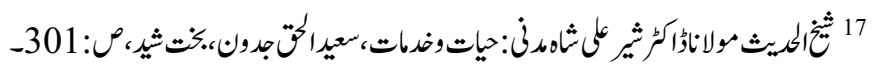

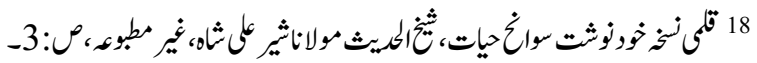

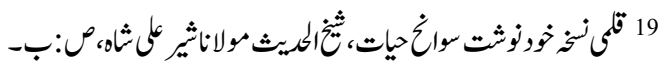




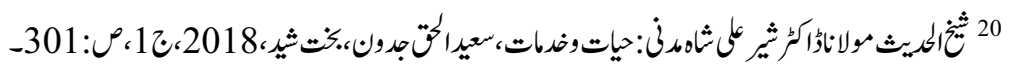

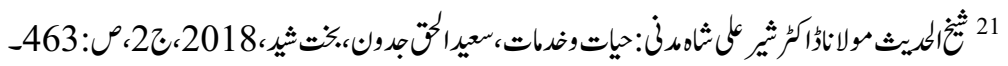

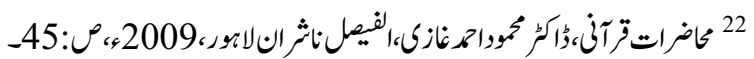

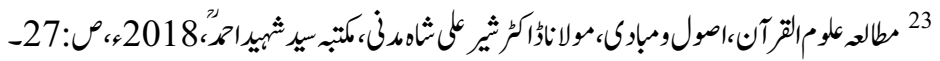

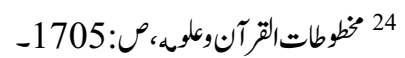

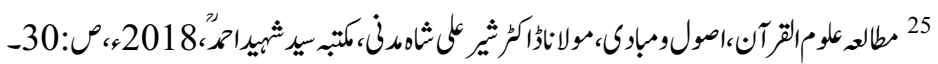

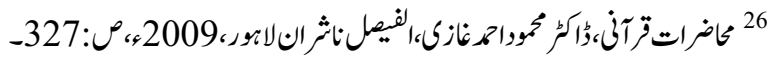

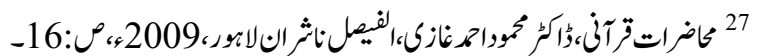

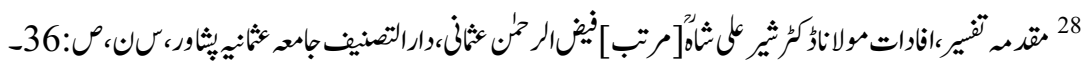

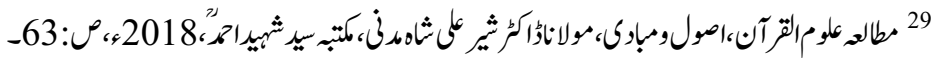
30

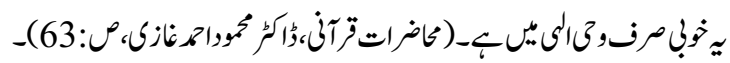

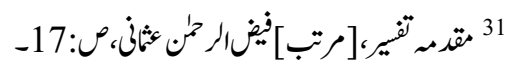

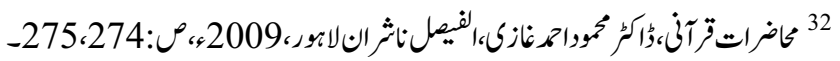

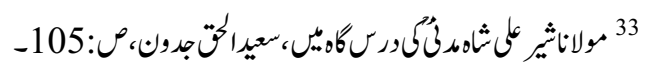

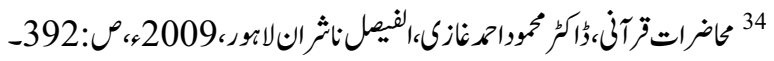

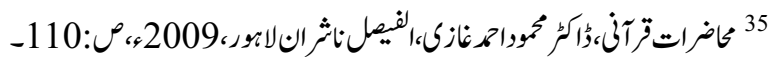

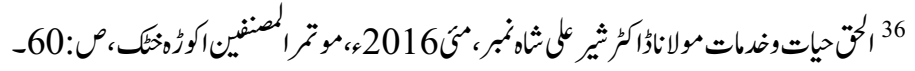

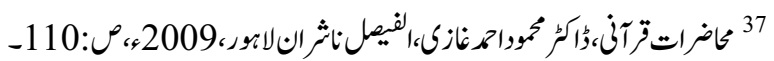

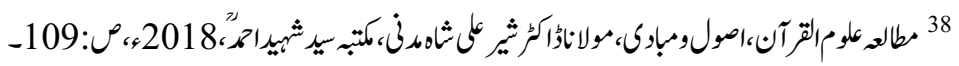

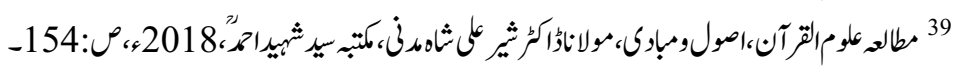

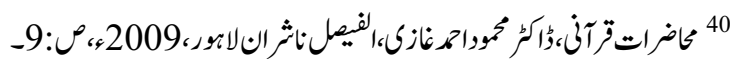

